\title{
Effect of different storage temperatures on the metabolic activity of spermatozoa following liquid storage of boar semen*
}

\author{
A. Dziekońska, L. Fraser and J. Strzeżek ${ }^{1}$ \\ Warmia and Mazury University in Olsztyn, \\ Department of Animal Biochemistry and Biotechnology \\ Oczapowskiego 5, 10-718 Olsztyn-Kortowo, Poland
}

(Received 5 February 2009; revised version 13 May 2009; accepted 6 November 2009)

\begin{abstract}
This study investigated the effects of different temperatures $\left(5^{\circ}\right.$ and $\left.16^{\circ} \mathrm{C}\right)$ on the metabolic activity of boar spermatozoa preserved in a standard semen extender, Kortowo 3 (K3), supplemented with or without egg yolk lipoprotein fractions (LPF) isolated from hen or ostrich egg yolk. Besides motility and plasma membrane integrity (PMI) assessments of spermatozoa, analysis of the metabolic activity of spermatozoa included mitochondrial energy status, oxygen uptake, ATP content and L-lactate production. Total motility and PMI of spermatozoa decreased over time. The metabolic activity of spermatozoa was significantly higher in the extenders containing LPF than in the K3 extender. Marked changes in the sperm metabolic activity observed during storage of semen samples at $5^{\circ} \mathrm{C}$ indicated that glycolysis (fructolysis) was the major metabolic pathway. It seemed likely that mitochondrial respiration was the predominant metabolic activity exhibited by spermatozoa during storage at $16^{\circ} \mathrm{C}$. The findings of this study indicate that different storage temperatures can modulate the metabolic pathways of boar spermatozoa during liquid semen storage.
\end{abstract}

KEY WORDS: boar, semen, spermatozoa, storage temperatures, metabolic activity

\footnotetext{
* Supported by Grants from the University of Warmia and Mazury in Olsztyn, No. 0103.206, the National Centre for Research and Development, No. 12001404, and the State Committee for Scientific Research, No. 2P06D 00228

${ }^{1}$ Corresponding autor: e-mail: strzezek@uwm.edu.pl
} 


\section{INTRODUCTION}

Mitochondrial respiration and anaerobic glycolysis are considered to be the major source of energy production in spermatozoa; however, these metabolic pathways vary among animal species (Mann and Lutwak-Mann, 1981; Strzeżek, 1998). Sugars such as glucose and fructose, and to some extent, sorbitol and mannose, are metabolized to pyruvic acid or lactate acid during glycolysis (Marin et al., 2003). It has been reported that boar spermatozoa have a limited capacity to metabolize exogenous substrates because they possess relatively low hexokinase activity (Medrano et al., 2005). A decline in the energy production by spermatozoa is associated with impaired mitochondrial oxidative phosphorylation, resulting in reduced motility (Thomas et al., 1998; Huo et al., 2002).

A gradual reduction in the metabolic activity of boar spermatozoa during storage at cold shock temperature could limit the production of detrimental by-products, which might compromise sperm function (de Leeuw et al., 1990; Althouse et al., 1998). It has been postulated that the components of the semen extender protect the sperm structures against the damaging effect of cold shock (Demianowicz and Strzeżek, 1996). Several studies in our laboratory have demonstrated that egg yolk lipoprotein fractions (LPF) provide excellent protection for the plasma membrane and acrosome integrity of boar spermatozoa against cold shock-related injury (Demianowicz and Strzeżek, 1996; Strzeżek et al., 1999, 2004, 2005; Fraser et al., 2002). More recently, acceptable fertility results in terms of farrowing rate and litter size were obtained when sows were artificially inseminated with LPFextended boar semen stored at $5^{\circ} \mathrm{C}$ (Strzeżek et al., 2006).

In a previous study we showed that the age of boars and seasons had a marked effect on sperm metabolic activity, characterized by oxygen uptake and ATP content, during liquid semen storage (Fraser et al., 2003). In this study, we investigated the effect of different storage temperatures $\left(5^{\circ}\right.$ and $\left.16^{\circ} \mathrm{C}\right)$ on the metabolic status of boar spermatozoa following storage of semen in a standard semen extender, Kortowo 3 (K3), supplemented with or without egg yolk lipoprotein fractions (LPF) isolated from hen egg yolk (K3-LPFh) or ostrich egg yolk (K3-LPFo). Besides motility and plasma membrane integrity assessments, parameters of the metabolic activity of spermatozoa included analysis of mitochondrial energy status, measurements of ATP content, oxygen uptake and L-lactate production. 


\section{MATERIAL AND METHODS}

\section{Animals and ejaculate collections}

Whole ejaculates were collected from 6 Polish Large White boars, aged 1.5 to 3 years. The boars were kept under standard hygienic conditions, and fed a commercial ration. The gloved-hand technique was used to collect ejaculates once per week from each boar over a 4-month period, beginning from September through December. A total of 96 ejaculates were collected and analysed for sperm quality characteristics, unless otherwise stated. At collections the gel portion was removed using double gauze. Only semen samples that had more than $70 \%$ sperm motility and less than $15 \%$ abnormal spermatozoa were used in this study. Spermatozoa were assessed for morphology (Watson, 1975) and counted using a haemocytometer. Permission to conduct this study was granted by the Local Ethics Committee.

\section{Processing and liquid storage of semen}

Semen samples were diluted $\left(30 \times 10^{6}\right.$ spermatozoa $\left./ \mathrm{ml}\right)$ in the following extenders: K3 extender $(69.3 \mathrm{mM}$ fructose, $64.6 \mathrm{mM}$ sodium citrate, $8.0 \mathrm{mM}$ $\mathrm{Na}_{2}$-EDTA, $14.2 \mathrm{mM}$ potassium acetate; $\mathrm{pH} 6.8,250 \mathrm{mg}$ gentamycin sulphate), $\mathrm{K} 3$ extender supplemented with 5\% (v/v) LPFh (K3-LPFh), and K3 extender supplemented with $5 \%(\mathrm{w} / \mathrm{v})$ LPFo (K3-LPFo). Lipoprotein fractions were isolated from hen and ostrich egg yolk, respectively, according to previously described methods (Demianowicz and Strzeżek, 1996; Strzeżek et al., 2005). Due to the large quantities of LPF extracts obtained from the ostrich egg yolk, we considered using lyophilization as a means of preserving these extracts for storage. Furthermore, research in our laboratory has shown that lyophilization does not have a significant effect on the biochemical composition of the LPF extracts (Strzeżek et al., 1999, 2005).

Diluted semen was equilibrated for $2 \mathrm{~h}$ at room temperature prior to cooling at $5^{\circ} \mathrm{C}$ (refrigerator) and $16^{\circ} \mathrm{C}$ (Thermobox, Minitüb Gmbh, Tiefenbach, Germany). Besides motility and plasma membrane integrity (PMI) assessments of spermatozoa, analysis of the metabolic activity of spermatozoa included mitochondrial energy status, oxygen uptake, ATP content and L-lactate production. Semen samples were analysed before cooling (Day 0), and after $48 \mathrm{~h}$ (Day 2) and $96 \mathrm{~h}$ (Day 3) of storage at $5^{\circ}$ or $16^{\circ} \mathrm{C}$. The number of sperm samples assessed for PMI $(n=35)$, mitochondrial function $(n=29)$ and L-lactate production $(n=45)$ was restricted due to the limited available supply of reagents. Furthermore, L-lactate 
production was determined only in semen samples before cooling (Day 0) and after $48 \mathrm{~h}$ of storage at both $5^{\circ}$ and $16^{\circ} \mathrm{C}$.

\section{Assessments of motility and plasma membrane integrity of spermatozoa}

Total motility of spermatozoa was assessed visually by the same technician throughout the study. For the assessments, aliquots $(6 \mu \mathrm{l})$ of diluted semen samples were placed on pre-warmed slide, covered with a glass cover slide and examined under a light microscope $(200 \times$ magnification $)$ equipped with an attached heated stage $\left(37^{\circ} \mathrm{C}\right)$.

Sperm plasma membrane integrity (PMI) was assessed using propidium iodide, PI (Sigma, St. Louis, MO, USA), as described in a previous study (Fraser et al., 2002). Membrane-damaged PI-stained spermatozoa were examined under an epifluorescence microscope (Olympus $\mathrm{CH}$ 30, Tokyo, Japan) and PMI was defined as the percentage of intact spermatozoa. Two slides were assessed per sample and 200 spermatozoa were evaluated per slide.

\section{Mitochondrial energy status assessed by fluorescent microscopy}

The mitochondrial energy status in spermatozoa was assessed using a fluorescent probe, 5,5',6,6'-tetrachloro-1,1',3,3'-tetraethylbenzimidazolylcarbocyanineiodide (JC-1) (Molecular Probes, Eugene, USA), according to a previously described method (Thomas et al., 1998), with some modifications. Briefly, semen samples $\left(30 \times 10^{6}\right.$ spermatozoa $\left./ 1 \mathrm{ml}\right)$ were washed $(600 \mathrm{~g}$, $5 \mathrm{~min}$ at room temperature) and the sperm pellets were re-suspended in a Hepes saline medium (130 mM NaCI, $4 \mathrm{mM} \mathrm{KCI}, 14 \mathrm{mM}$ fructose, $10 \mathrm{mM}$ Hepes, $1 \mathrm{mMCaC1}_{2}, 0.5 \mathrm{mM} \mathrm{MgC1}{ }_{2}, 0.1 \%$ BSA). Three microliters of JC- 1 solution ( $1 \mathrm{mg}$ $\mathrm{JC}-1 / \mathrm{ml}$ anhydrous dimethyl sulphoxide) were added to aliquots $(1 \mathrm{ml})$ of washed sperm samples and incubated for $15 \mathrm{~min}$ at $37^{\circ} \mathrm{C}$. Following incubation, sperm samples were counterstained with PI $(10 \mu 1$ of PI solution in $0.5 \mathrm{mg} / \mathrm{ml}$ phosphate buffered solution) in order to allow identification of non-viable spermatozoa with compromised mitochondrial function. Aliquots $(10 \mu \mathrm{l})$ of stained sperm samples were examined under an epifluorescence microscope. Viable spermatozoa with high mitochondrial energy status emitted orange-red fluorescence. Two slides were evaluated per sample and 200 spermatozoa were counted per slide.

\section{Oxygen uptake}

Oxygen uptake was measured polargraphically in a Yellow Springs oxygen monitor (YSI 5300 Biological Oxygen Monitor, Co., Inc., Yellow Springs, 
Ohio, USA) equipped with a Clarke's electrode, according to the manufacturer's instruction manual. Oxygen measurements were expressed as $\mu l \mathrm{O}_{2} / 10^{8}$ spermatozoa $/ 1 \mathrm{~h} / 37^{\circ} \mathrm{C}\left(\mathrm{ZO}_{2}\right)$.

\section{ATP content}

The ATP content in spermatozoa was assessed using a bioluminescence kit (ATP Bioluminescence Assay Kit CLSII; Roche Molecular Biochemical). Prior to assay, $100 \mu \mathrm{l}$ aliquots of sperm suspension $\left(30 \times 10^{6}\right.$ spermatozoa $\left./ 1 \mathrm{ml}\right)$ were added to TRIS buffer $(900 \mu \mathrm{l})$ containing $4 \mathrm{mM}$ EDTA $(\mathrm{pH} 7.75)$ and then boiled for 5 min. After boiling and cooling, $100 \mu \mathrm{l}$ sperm extract were added to $100 \mu \mathrm{l}$ assay kit. Measurements of ATP content were performed using a Junior Bioluminometer (Berthold Technologies, $\mathrm{GmbH}$ and Co. KG, Germany), according to the assay kit protocol. The ATP content in spermatozoa was calculated from an ATP standard curve and expressed as nmol ATP $/ 10^{8}$ spermatozoa.

\section{L-lactate production as a marker for the rate of fructolysis}

The rate of L-lactate production in spermatozoa was determined, as described in a previous study (Rodriguez-Gil and Rigau, 1995), with some modifications. Extended semen samples were washed twice ( $600 \mathrm{~g}, 5 \mathrm{~min}$ at room temperature) in K3 extender in order to remove exogenous substrates. Sperm pellets $(100 \times$ $10^{6}$ spermatozoa $/ \mathrm{ml}$ ) were re-suspended in a buffer containing $2.94 \%(\mathrm{w} / \mathrm{v})$ sodium citrate and $5.4 \%(\mathrm{w} / \mathrm{v})$ fructose $(\mathrm{pH} 7.4)$ and incubated for $1 \mathrm{~h}$ at $37^{\circ} \mathrm{C}$. Following incubation, the mixture was centrifuged, as mentioned above. L-lactate production by spermatozoa was measured in the supernatant using a reagent kit (Pointe Scientific Inc., Canton, Michigan, USA). Absorbances was measured spectrophotometrically (Beckman $\mathrm{DU}^{\circledR}$ - 62) at a wave length of $550 \mathrm{~nm}$. The L-lactate production was expressed as $\mathrm{nmol} / 10^{8} / 1 \mathrm{~h} / 37^{\circ} \mathrm{C}$.

\section{Statistical analysis}

Data were subjected to analysis of variance (ANOVA) using the General Linear Model (GLM) procedure from the Statistica software package, version 8 (StatSoft Incorporation, Tulsa OK, USA). The statistical model used to investigate the effects of extender type, storage temperature, storage time and their interactions on sperm motility, plasma membrane integrity mitochondrial energy status, oxygen uptake and ATP content included a mixed factorial design $(3 \times 2 \times 2)$. The effects of extender type and storage temperature and their interactions on L-lactate production were investigated with a $3 \times 2$ factorial design. All results are 
expressed as the mean \pm standard error of the mean (SEM), and were considered significant at $\mathrm{P}<0.05$.

\section{RESULTS}

ANOVA results regarding sperm quality characteristics in liquid-stored semen are shown in Table 1. The main effects of extender type, storage temperature and storage time significantly affected $(\mathrm{P}<0.001)$ all of the analysed sperm quality characteristics. In addition, it was observed that only the interaction between extender type $\times$ storage temperature exerted a significant effect on sperm quality characteristics.

Table 1. ANOVA sources of variations in sperm quality characteristics following liquid storage of boar semen

\begin{tabular}{|c|c|c|c|c|c|c|c|}
\hline \multirow[t]{2}{*}{ Source } & \multirow[t]{2}{*}{ df } & \multicolumn{2}{|c|}{ Motility } & \multicolumn{2}{|c|}{$\begin{array}{c}\text { Plasma membrane } \\
\text { integrity }\end{array}$} & \multicolumn{2}{|c|}{$\begin{array}{c}\text { Mitochondrial } \\
\text { energy status }\end{array}$} \\
\hline & & F-test & P-value & F-test & P-value & F-test & P-value \\
\hline Extender type & 2 & 729.16 & 0.001 & 216.09 & 0.001 & 259.72 & 0.001 \\
\hline Storage temperature & 1 & 17.52 & 0.001 & 48.24 & 0.001 & 103.23 & 0.001 \\
\hline Storage time & 1 & 274.36 & 0.001 & 48.11 & 0.001 & 21.10 & 0.001 \\
\hline \multicolumn{3}{|l|}{ Extender type $\times$ storage } & 0.021 & 20.24 & 0.001 & 19.55 & 0.001 \\
\hline \multirow{2}{*}{ Source } & \multirow{2}{*}{ df } & \multicolumn{2}{|c|}{ Oxygen uptake } & \multicolumn{2}{|c|}{ ATP content } & & \\
\hline & & F-test & P-value & F-test & P-value & & \\
\hline Extender type & 2 & 77.93 & 0.001 & 41.86 & 0.001 & & \\
\hline Storage temperature & 1 & 152.02 & 0.001 & 103.47 & 0.001 & & \\
\hline Storage time & 1 & 20.70 & 0.001 & 80.71 & 0.001 & & \\
\hline $\begin{array}{l}\text { Extender type } \times \text { storage } \\
\text { temperature }\end{array}$ & 2 & 5.27 & 0.005 & 3.73 & 0.005 & & \\
\hline $\begin{array}{l}\text { ANOVA was used to an } \\
\text { K3-LPFo), storage tempe } \\
\text { F - Fisher test; K3 - K } \\
\text { lipoprotein fractions isol } \\
\text { with lipoprotein fractions }\end{array}$ & 2 & $\begin{array}{l}\text { he interac } \\
\left(5^{\circ} \mathrm{C} ; 16^{\circ} \mathrm{C}\right. \\
\text { extender } \\
\text { om hen e }\end{array}$ & $\begin{array}{l}\text { ions of } t \\
\text { and stor } \\
\text { LPFh - } \\
\text { g yolk; I }\end{array}$ & $\begin{array}{l}\text { nain effe } \\
\text { time (Da } \\
\text { towo } 3 \\
\text { - Korto }\end{array}$ & $\begin{array}{l}\text { 8: exten } \\
\text { 2; Day } 3 \\
\text { 3) exte } \\
3 \text { (K3 }\end{array}$ & $\begin{array}{l}\text { e }(\mathrm{K} 3 \\
\text { legree } \\
\text { upplem } \\
\text { der su }\end{array}$ & $\begin{array}{l}\text { 3-LPFh; } \\
\text { freedom; } \\
\text { led with } \\
\text { lemented }\end{array}$ \\
\hline
\end{tabular}

Means \pm SEM for motility and PMI of spermatozoa during liquid semen storage are shown in Table 2 . Total motility of spermatozoa decreased continuously over time $(\mathrm{P}<0.05)$ during storage, being less marked in both K3-LPFh and K3-LPFo extenders. There was a gradual deterioration in PMI of spermatozoa during storage in $\mathrm{K} 3$ extender. Furthermore, marked changes in PMI were more evident 


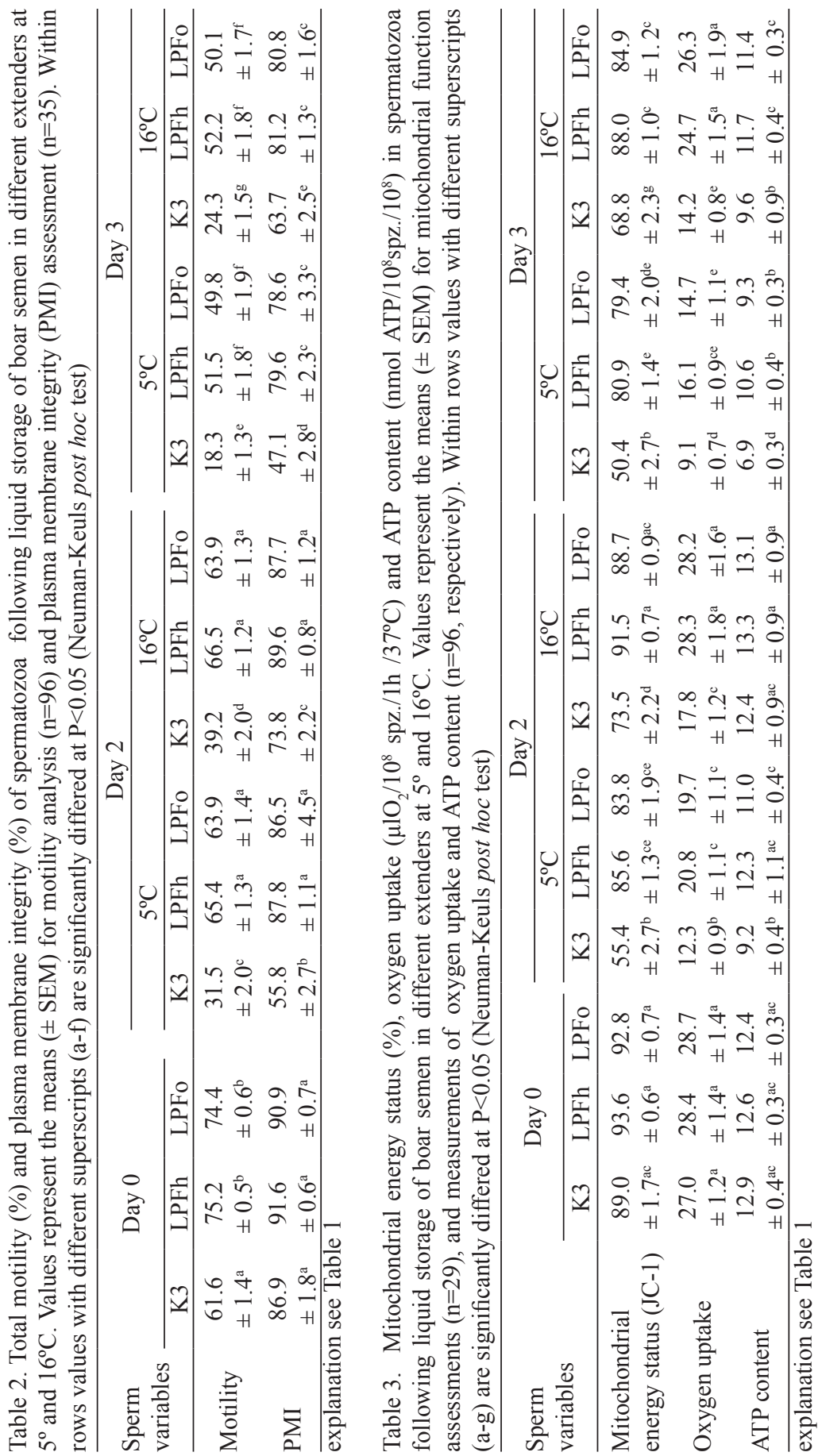


on Day 3 of storage in the extenders containing LPF, regardless of the storage temperature. Within respective storage time, there were no significant changes $(\mathrm{P}>0.05)$ in total motility or PMI of spermatozoa between semen samples stored at $5^{\circ}$ and $16^{\circ} \mathrm{C}$ in either K3-LPFh or K3-LPFo extender.

Means \pm SEM for mitochondrial energy status, oxygen uptake and ATP content in spermatozoa during liquid semen storage are shown in Table 3. Compared with $\mathrm{K} 3$ extender spermatozoa stored in either K3-LPFh or K3-LPFo extender exhibited higher mitochondrial energy status, as assessed by the JC-1 fluorescent probe. Moreover, marked changes in the mitochondrial energy status of spermatozoa were more evident during storage at $5^{\circ} \mathrm{C}$, particularly in $\mathrm{K} 3$ extender. It was observed that spermatozoa stored at $5^{\circ} \mathrm{C}$ exhibited a marked decline $(\mathrm{P}<0.05)$ in oxygen uptake and ATP content compared with those stored at $16^{\circ} \mathrm{C}$. Furthermore, oxygen uptake by spermatozoa did not differ over time $(\mathrm{P}>0.05)$ during storage in the extenders containing LPF at $16^{\circ} \mathrm{C}$. There were no marked differences in ATP content in spermatozoa prior to cooling (Day 0) or on Day 3 of storage in both K3-LPFh and K3-LPFo extenders.

ANOVA results showed that the rate of L-lactate production was significantly affected by the extender type (d.f. $=2, \mathrm{~F}=21.56, \mathrm{P}<0.001$ ) and storage temperature (d.f. $=1, \mathrm{~F}=150.13, \mathrm{P}<0.001$ ). Compared with $\mathrm{K} 3$ extender, spermatozoa stored in either K3-LPFh or K3-LPFo extender exhibited a greater $(\mathrm{P}<0.05)$ rate of fructolysis, as indicated by the higher levels of L-lactate production (Table 4). Furthermore, the rate of fructolysis was markedly suppressed $(\mathrm{P}<0.05)$ in spermatozoa stored at $5^{\circ} \mathrm{C}$ compared with those stored at $16^{\circ} \mathrm{C}$, irrespective of the extender type.

Table 4. Lactate production $\left(\mathrm{nmol} / 10^{8} / 1 \mathrm{~h} / 37^{\circ} \mathrm{C}\right)$ by spermatozoa during liquid storage of boar semen in different extenders at $5^{\circ}$ i $16^{\circ} \mathrm{C}$. Values represent the means $( \pm \operatorname{SEM})(n=45)$. Within rows values with different superscripts (a-f) are significantly differed at $\mathrm{P}<0.05$ (Neuman-Keuls post hoc test)

\begin{tabular}{|c|c|c|c|c|c|c|c|c|}
\hline \multirow{2}{*}{\multicolumn{3}{|c|}{ Day 0}} & \multicolumn{6}{|c|}{ Day 3} \\
\hline & & & \multicolumn{3}{|c|}{$5^{\circ} \mathrm{C}$} & \multicolumn{3}{|c|}{$16^{\circ} \mathrm{C}$} \\
\hline K3 & LPFh & LPFo & K3 & LPFh & LPFo & K3 & LPFh & LPFo \\
\hline 653.1 & 635.5 & 608.5 & 229.4 & 340.2 & 265.7 & 369.1 & 502.4 & 490.0 \\
\hline $\pm 30.8^{\mathrm{a}}$ & $\pm 31.2^{\mathrm{a}}$ & $\pm 33.3^{\mathrm{a}}$ & $\pm 18.4^{\mathrm{b}}$ & $\pm 23.8^{\mathrm{cf}}$ & $\pm 18.2^{\mathrm{c}}$ & $\pm 26.4^{\mathrm{df}}$ & $\pm 25.7^{\mathrm{e}}$ & $\pm 20.5^{\mathrm{e}}$ \\
\hline
\end{tabular}

explanation see Table 1

\section{DISCUSSION}

Liquid boar semen is usually stored at $15^{\circ}$ to $20^{\circ} \mathrm{C}$ due to sperm susceptibility to cold shock damage (Pursel et al., 1972; Parks and Lynch, 1992). Sperm motility 
is commonly used to evaluate the quality of liquid-stored semen at artificial insemination (AI) stations because it is one of parameters that is most seriously affected during storage. There were no marked changes in motility and PMI of spermatozoa during storage in the LPF-extended semen on days 2 and 3 at $5^{\circ} \mathrm{C}$ compared with those stored at $16^{\circ} \mathrm{C}$, indicating the protective action of egg yolk lipoprotein fractions against cold shock-induced damage.

In the present study, sperm mitochondrial energy status was monitored with a mitochondria-selective fluorescent probe, JC-1, which enabled measuring membrane potentials measurements. Furthermore, the relatively high ATP content in spermatozoa observed in the LPF-extended semen might suggest that impairment of sperm motility was not clearly related to mitochondrial function. Using a bioluminescence assay, a previous study also reported that there were no significant changes in ATP content in boar spermatozoa preserved in Beltsville Thawing Solution (BTS) at $17^{\circ} \mathrm{C}$ (Long and Guthrie, 2006). It is noteworthy that ATP production, a sensitive metabolic function of spermatozoa, is directly linked to mitochondrial oxidative phosphorylation (Strzeżek, 1998). We suggested that the addition of egg yolk lipoprotein fractions to the semen extender helped to reinforce the stability of the plasma membrane of spermatozoa, thereby rendering them less susceptible to damage incurred during liquid storage, particularly at $5^{\circ} \mathrm{C}$. It seemed likely that differences in the mitochondrial energy status of spermatozoa between semen samples stored at $5^{\circ}$ and $16^{\circ} \mathrm{C}$ were not related to changes in sperm motility and plasma membrane integrity. Furthermore, the results of the current study indicate that cooled-storage of semen in $\mathrm{K} 3$ extender compromised sperm metabolic function.

It has been hypothesized that the ATP concentrations required for sperm motility are provided by mitochondrial respiration and glycolysis (Mukai and Okuno, 2004). Moreover, it is still under debate whether the ATP produced by the mitochondria can be delivered in sufficient quantities to supply the entire sperm flagellum (Westhoff and Kamp, 1997). It is important to emphasize that glycolytic ATP production in the principal tail piece of spermatozoa may compensate for the insufficient transport system of ATP to the distal dynein ATP-ases (Halang et al., 1985; Kamp et al., 1996). It has been postulated that boar spermatozoa are almost totally reliant on the mitochondrial respiration pathway due to the low energy output contributed by glycolysis/fructolysis (Strzeżek, 1998). This assertion is reinforced by the fact that the rate of fructose utilization by boar spermatozoa is significantly lower than in other animal species, probably due to the relatively low hexokinase activity (Medrano et al., 2005). Besides mitochondrial respiration and glycolysis, boar spermatozoa can utilize non-hexose substrates through other metabolic pathways to maintain the optimal energy level required for their basic functions (Medrano et al., 2005). 
Boar spermatozoa are able to produce L-lactate during glycolysis and under aerobic conditions (Jones, 1997). During storage in the LPF-extended semen at $5^{\circ} \mathrm{C}$, the reduction in L-lactate production by spermatozoa, accompanied by a decline in oxygen uptake and ATP content, indicates that glycolysis (fructolysis) was the primary source of the sperm energy pathway. In contrast, spermatozoa stored in the LPF-extended semen at $16^{\circ} \mathrm{C}$ relied more on mitochondrial respiration as their main energy pathway. The differences in energy metabolism observed during storage of semen at $5^{\circ}$ and $16^{\circ} \mathrm{C}$ indicated that spermatozoa could directly modulate the consumption of energy substrates in response to varying environmental conditions. The findings of the current study suggest that spermatozoa stored at $5^{\circ} \mathrm{C}$ were able to conserve their metabolic activity, which is needed during cooling of semen prior to cryopreservation. Furthermore, the reliance of liquid semen during storage at $5^{\circ} \mathrm{C}$ on the glycolytic pathway as the principal source of energy reaffirmed that spermatozoa can modulate their energy metabolism to adapt to the extracellular environment when under found in stressful conditions. Such a feature is of particular importance during semen cryopreservation.

\section{CONCLUSIONS}

In conclusion, these findings reinforce and support the view that the metabolic activity of boar spermatozoa preserved in extenders containing egg yolk lipoproteins is affected by the different storage temperatures. Furthermore, the findings of this study indicate that both glycolysis and mitochondrial respiration are important metabolic pathways of boar spermatozoa that should be considered in improving semen preservation. Finally, further studies on the fundamental energy metabolism of spermatozoa are needed to develop optimal liquid storage and cryopreservation conditions for boar semen.

\section{REFERENCES}

Althouse G.C., Wilson M.E., Kuster C., Parsley M., 1998. Characterization of lower temperature storage limitations of fresh-extended porcine semen. Theriogenology 50, 535-543

de Leeuw F.E., Chen H.C., Colenbrander B., Verkleij A.J., 1990. Cold-induced ultrastructural changes in bull and boar sperm plasma membranes. Cryobiology 27, 171-183

Demianowicz W., Strzeżek J., 1996. The effect of lipoprotein fraction from egg yolk on some of the biological properties of boar spermatozoa during storage of the semen in liquid state. Reprod. Domest. Anim. 31, 279-280 
Fraser L., Gorszczaruk K., Lecewicz M., Strzeżek J., 2003. Age-related changes and seasonal variation in boar sperm metabolism during liquid storage at $5^{\circ}$ and $16^{\circ} \mathrm{C}$. J. Anim. Feed Sci. $12,805-813$

Fraser L., Lecewicz M., Strzeżek J., 2002. Fluorometric assessments of viability and mitochondrial status of boar spermatozoa following liquid storage. Pol. J. Vet. Sci. 5, 85-92

Jones A.R., 1997. Metabolism of lactate by mature boar spermatozoa. Reprod. Fert. Develop. 9, 227-232

Halang W., Bohnensack R., Kunz W., 1985. Interdependence of mitochondrial ATP production and extramitochondrial ATP utilization in intact spermatozoa. Biochim. Biophys. Acta 808, 316322

Huo L.J., Ma X., Yang Z.M., 2002. Assessment of sperm viability, mitochondrial activity, capacitation and acrosome intactness in extended boar semen during long-term storage. Theriogenology 58 , $1349-1360$

Kamp G., Büsselmann G., Lauterwein J., 1996. Spermatozoa: models for studying regulatory aspects of energy metabolism. Experientia 52, 487-494

Long J.A., Guthrie H.D., 2006. Validation of a rapid, large-scale assay to quantify ATP concentration in spermatozoa. Theriogenology 65, 1620-1630

Mann T., Lutwak-Mann C., 1981. Biochemistry of seminal plasma and male accessory luids, application to andrological problems. In: T. Mann, C. Lutwak-Mann (Editors). Male Reproductive Function and Semen. Themes and Trends in Physiology, Biochemistry and Investigate Andrology. Berlin-Heidelberg (Germany) and New York, NY. Springer-Verlag, pp. 269-336

Marin S., Chiang K., Bassilian S., Lee W.N., Boros L.G., Fernandez-Novell J.M., Centelles J.J., Medrano A., Rodriguez-Gil J.E., Cascante M., 2003. Metabolic strategy of boar spermatozoa revealed by a metabolic characterization. FEBS Lett. 554, 342-346

Medrano A., Peňa A., Rigau T., Rodríguez-Gil J.E., 2005. Variations in the proportion of glycolytic/ non-glycolytic energy substrates modulate sperm membrane integrity and function in diluted boar samples stored at $15-17^{\circ} \mathrm{C}$. Reprod. Domest. Anim. 40, 448-453

Mukai C., Okuno M., 2004. Glycolysis plays a major role for adenosine triphosphate supplementation in mouse sperm flagellar movement. Biol. Reprod. 71, 540-547

Parks J.E., Lynch DV., 1992. Lipid composition and thermotropic behaviour of boar, bull, stallion and rooster sperm membranes. Cryobiology 29, 255-266

Pursel V.G., Johnson L.A., Schulman L.L., 1972. Interaction of extender composition and incubation period on cold shock susceptibility of boar spermatozoa. J. Anim. Sci. 35, 580-584

Rodriguez-Gil J.E., Rigau T., 1995. Effects of slight agitation on the quality of refrigerated boar sperm. Anim. Reprod. Sci. 34, 141-146

Strzeżek J., 1998. Physiology and biochemical structures of mammalian spermatozoa. In: A. Łukaszczyk, B. Bilińska, J. Kawiak, Z. Bielańska-Osuchowska (Editors). Ultrastructure and Cell Functions. Polish Scientific Publishers, Warsaw, 7, 99-126

Strzeżek J., Fraser L., Dziekońska A., Lecewicz M., 2006. Complexity of technology reservation of boar semen - fundamental and applicative approaches. Reprod. Domest. Anim. 41, 325 (Abstr.)

Strzeżek J., Fraser L., Kuklińska M., Dziekońska A., Lecewicz M., 2004. Effects of dietary supplementation with polyunsaturated fatty acids and antioxidants on biochemical characteristics of boar semen. Reprod. Biol. 4, 271-287

Strzeżek J., Lecewicz L., Dziekońska A., Fraser L., 2005. A simple method of extraction of lipoprotein fractions from avian egg yolk - protective effect on cooled boar semen. Theriogenology 63, 496497 
Strzeżek J., Lecewicz M., Fraser L., 1999. Ostrich egg yolk as a component of an extender for liquid preservation of boar semen at $5^{\circ}$ and $16^{\circ} \mathrm{C}$. Abstract of the 3 rd Annual Conference of the European Society for Domestic Animal Reproduction (ESDAR). Anger (France), p. 86

Thomas C.A., Garner D.L., De Jarnette J.M., Marshall C.E., 1998. Effect of cryopreservation on bovine sperm organelle function and viability as determined by flow cytometry. Biol. Reprod. $58,786-793$

Watson P.F., 1975. Use of Giemsa stain to detect changes in acrosomes of frozen ram spermatozoa. Vet. Rec. 97, 12-15

Westhoff D., Kamp G., 1997. Glyceraldehyde 3-phosphate dehydrogenase is bound to the fibrous sheath of mammalian spermatozoa. J. Cell Sci. 110, 1821-1829 